\title{
Fascin Expression in Ameloblastoma, Odontogenic Keratocyst and Dentigerous Cyst
}

\author{
Sedigheh RAHROTABAN' ${ }^{\text {, Nariman NIKPARTO², Parham YOUSEFIZADEH }}{ }^{3}$, \\ Mohammad Javad KHARAZIFARD ${ }^{4}$, Samira DERAKHSHAN ${ }^{1}$
}

'Department of Oral and Maxillofacial Pathology, ${ }^{2}$ Oral and Maxillofacial Surgery Resident, Tehran University of Medical Sciences, School of Dentistry, TEHRAN, IRAN ${ }^{3}$ Dentist, Private Practice, TEHRAN, IRAN, ${ }^{4}$ Dental Research Center, Dentistry Research Institute, Tehran University of Medical Sciences, TEHRAN, IRAN

\begin{abstract}
Objective: The purpose of this study was to assess and compare fascin expression in 4 lesions which differ in aggressiveness: odontogenic keratocyst, dentigerous cyst and two types of ameloblastoma (solid and unicystic), and to find out whether fascin expression is associated with aggressiveness of these lesions or not.
\end{abstract}

Material and Method: Nine solid ameloblastomas , 12 unicystic ameloblastomas, 13 odontogenic keratocyst and 12 dentigerous cyst were assessed in this study. The slides were examined at x400 magnification. Finally the lesions were divided into two groups based on microscopic examination, "low expression" and "high expression".

Results: There were no significant differences between the lesions, except that fascin expression was slightly higher in unicystic ameloblastomas in comparison to other groups in intensity and count of the immunostaining cells.

Conclusion: The results of this study suggest that local aggressiveness does not result in fascin expression. We suggest more studies with more samples, assessing expression of different proteins be done in the future.

Key Words: Ameloblastoma, Dentigerous cyst, Fascin, Odontogenic keratocyst

\section{INTRODUCTION}

Fascin is a known $55-\mathrm{kDa}$ globular actin-bundling protein which is mainly expressed in cell membrane protrusions like microspikes called filopodia. This protein has three isoforms in mammals: Fascin-1 (referred to from here on as Fascin) which is highly expressed in neural and mesenchymal tissues during embryogenesis and in brain, endothelium and testis in adults, fascin-2 in retina and fascin-3 in testes (1-3). Fascin is mainly expressed in neurons, dendritic cells and pericytes which have striking large filopodia and which are highly mobile (4-6). Also this protein is expressed in endothelial cells and fibroblasts (7, 8). Fascin expression has been found to be low or absent in the majority of normal adult epithelial tissue varying origin. However, in stratified squamous cells of skin, fascin is expressed at a very low intensity and only in the basal layer $(9,10)$. Frequent and increased fascin expression in healthy, although tumor-adjacent, epithelial tissue has previously been reported (10).

Epithelial cell junctions are mostly dependent on cellcell or cell-matrix interactions which help to stabilize the

(Turk Patoloji Derg 2018, 34:220-224)

Received : 15.10.2017 Accepted : 23.05.2018 epithelial cells and prevent their migration. In epithelial malignancies, invasion to basal lamina and metastasis occurs due to elimination of these junctions. Fascin is considered in the migration and invasion of carcinoma cells since this actin-cross-linking protein is known to be responsible for controlling the guiding system of cell migration.

Many studies have reported the upregulation of fascin expression in various tumors. Moreover it has been reported that high expression of fascin is associated with high motility of cells, poor differentiation, advanced grade and stage and metastasis $(11,12)$. Fascin helps to stabilize the actin bundles in protrusions and it therefore seems to be used by cancerous cells to assemble stable and durable invasive protrusions (called invadopodia) that help invasion into the matrix $(13,14)$.

Ameloblastoma is slow growing and locally aggressive odontogenic epithelial tumor with a low tendency to metastasize and a high recurrence rate (15).

Odontogenic keratocyst (OKC), formerly known as keratocystic odontogenic tumor (KCOT), is a common

Correspondence: Samira DERAKHSHAN

Tehran University of Medical Sciences,

Department of Oral and Maxillofacial Pathology, TEHRAN, IRAN

E-mail: sderakhshan@tums.ac.ir Phone: +0098218 8351163 
odontogenic cyst that originates from the dental lamina or from its residue; occurring at any age, and is more common in men than women with a 2:1 ratio (16). Because of the high proliferation rate, aggressiveness and recurrence rate of epithelial cells of this cyst, in 2005 WHO reclassified odontogenic keratocyst as benign intra-osseous neoplasia, called KCOT (17). However, this odontogenic lesion is now listed as odontogenic keratocyst in the 2017 classification of developmental odontogenic cysts (16).

Dentigerous cyst (DC) is the second most common odontogenic cyst (following radicular cyst) which is typically seen as a radiolucency surrounding the crown of an impacted tooth. DC is not as aggressive as ameloblastoma or OKC (18).

In this article, we assessed and compared fascin expression in 4 lesions which differ in aggressiveness: OKC, two types of ameloblastoma (solid -which is believed to be more aggressive- and Unicystic) and DC to find out whether the fascin expression is associated with aggressiveness of these lesions or not.

\section{MATERIAL and METHODS}

Due to the retrospective nature of this study, it was granted an exemption in writing by the institutional review board of Tehran University of Medical Sciences (TUMS). For this descriptive analytic study, 82 biopsy-proven samples were retrieved from the archives of Departments of Oral and Maxillofacial Pathology of Tehran and Qazvin University of Medical Sciences. A total of 36 cases were excluded because of quantitatively inadequate available tissue in paraffin blocks, and recurrent or inflammatory lesions.

Thus, 46 paraffin blocks including 9 solid ameloblastomas (SA), 12 unicystic ameloblastomas (UA), 13 OKCs and 12 DCs were assessed in this study.

After obtaining sections with a thickness of $4 \mu \mathrm{m}$, immunohistochemical staining was carried out with the monoclonal anti-fascin antibody (Clone 55K-2 Dako, Glostrup, Denmark) diluted 1:50. For each case, a section with the primary antibody omitted was used as negative control and the cytoplasm of endothelial cells was used as internal positive control.

In microscopic assessment, the slides were examined at $\mathrm{x} 400$ magnification (Figure 1A-F) by an oral and maxillofacial pathologist who was blinded to the clinical characteristics of the samples. Immunoexpression of fascin in tumor cells was evaluated in terms of extent and intensity. The extent of immunostaining was scored according to Terence K. Lee (19): 1-negative: less than 10\% of cells, 2 -weak: $11-50 \%$ of cells, 3-moderate: $51-80 \%$ of cells and 4-strong: more that $81 \%$ of cells. Moreover, the staining intensity of the samples was categorized according to the cytoplasmic staining of cells into: 1-faint, 2-moderate and 3-severe. Finally, to determine the expression level of fascin, a Combined Immunoreactivity Score (CIS) was calculated by adding the score of extent to the score of intensity for each case. The samples were further classified into 4 groups: Negative expression: staining in less than $10 \%$ of cells regardless their staining intensity, weak expression: CIS equal to 3 , moderate expression: CIS equal to 4 or 5 , strong expression: CIS equal to 6 or 7 .

In statistical analyses, the first 2 groups were merged as the "low expression" group, and the groups 3 and 4 merged as the "high expression" group. Research data were analyzed using the Statistical Package for Social Sciences (SPSS), version 18. The Kruskal-Wallis and two by two Dunn Tests were used. P values less than 0.05 were considered significant.

\section{RESULTS}

The scores of stained-cell counts, staining intensities and CIS are shown in Table I. Ten samples from 12 unicystic ameloblastoma (83.3\%) showed a score of 3 in intensity and also 10 samples showed a score of 4 in the count of immunostaining cells (Table I). As mentioned formerly, these four groups were merged into low expression (group $1 \& 2$ ) and high expression (group 3\&4). No significant difference was found between these groups $(\mathrm{P}>0.05)$. All the samples of the four groups (DC, OKC, SA and UA) were classified in the high expression group except one sample of OKC $(7.7 \%)$ that was classified in the low expression group (Table I). In the two by two comparison test, although a significant $P$ value was seen in UA comparison with other lesions, there was no significant difference between the groups when other criteria were considered in the statistical tests.

\section{DISCUSSION}

Four different tumors based on aggressiveness of their clinical behavior were studied in this study. The aggressive behavior of OKC was close to ameloblastoma as in many studies which investigated the expression of markers such as p53, p63, Ki67, PCNA, AgNors and Ipo (20-23) and concluded that the proteins expressed on epithelial cells of OKC is more alike to that of ameloblastoma than DC.

In order to assess aggressiveness of lesions, some studies have examined the extra cellular matrix and connective tissue proteins such as fibronectin, laminin, tenascin, RANK, RANKL, and OPG in these lesions. Many of them found significant differences in the expression levels of these proteins among DC, ameloblastoma and OKC (2427). 

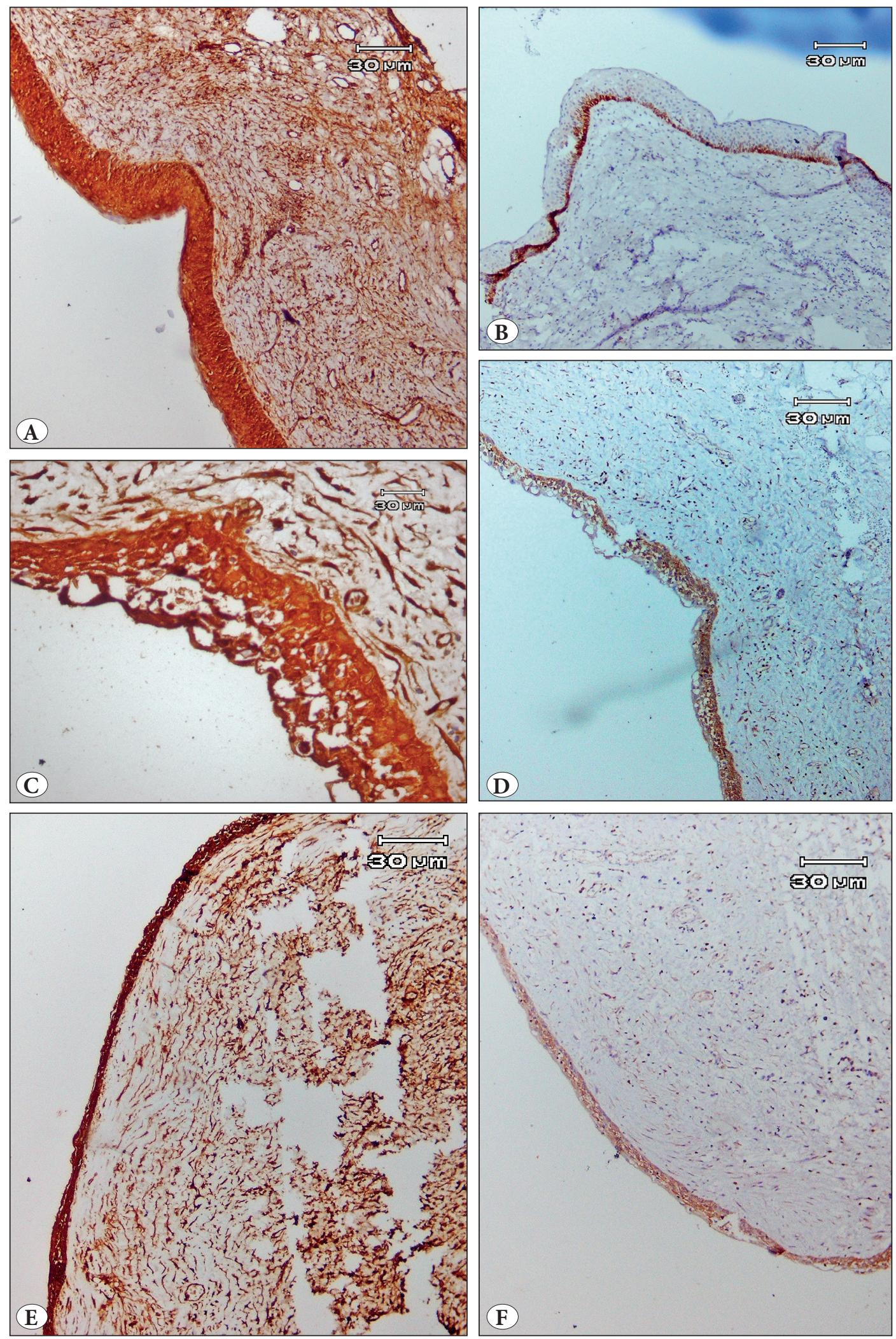

Figure 1: A) High expression of fascin in basal and suprabasal layers in odontogenic keratocyst. Note immunoactivity of stomal fibroblasts and endothelial cells as positive internal control (IHC; x100). B) Low expression of fascin only in basal layer in odontogenic keratocyst (IHC; x100). C) High expression of fascin in basal and suprabasal stratum reticulum layers in unicyctic ameloblastoma (IHC; 4 400). D) Low expression of fascin in unicyctic ameloblastoma. Note immunoactivity of stromal fibroblasts and endothelial cells even in low epithelial lining reaction (IHC; x100). E) High expression of fascin in dentigerous cyst (IHC; x100). F) Low expression of fascin in dentigerous cyst (IHC; x100). 
Table I: Scores of stained-cell counts, staining intensities and group classifications based on immunohistochemical assessments

\begin{tabular}{|c|c|c|c|c|c|c|c|}
\hline & & & \multicolumn{4}{|c|}{ Lesion } & \multirow[b]{2}{*}{ Total } \\
\hline & & & $\begin{array}{c}\text { solid } \\
\text { ameloblastoma }\end{array}$ & $\begin{array}{c}\text { odontogenic } \\
\text { keratocyst }\end{array}$ & $\begin{array}{c}\text { dentigerous } \\
\text { cyst }\end{array}$ & $\begin{array}{c}\text { unicystic } \\
\text { ameloblastoma }\end{array}$ & \\
\hline \multirow{6}{*}{ 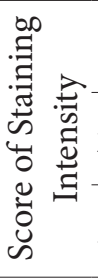 } & & Count & 1 & 2 & 2 & 0 & 5 \\
\hline & & $\%$ within pathology & $11.10 \%$ & $15.40 \%$ & $16.70 \%$ & $0.00 \%$ & $10.90 \%$ \\
\hline & & Count & 5 & 6 & 6 & 2 & 19 \\
\hline & & \% within pathology & $55.60 \%$ & $46.20 \%$ & $50.00 \%$ & $16.70 \%$ & $41.30 \%$ \\
\hline & & Count & 3 & 5 & 4 & 10 & 22 \\
\hline & & \% within pathology & $33.30 \%$ & $38.50 \%$ & $33.30 \%$ & $83.30 \%$ & $47.80 \%$ \\
\hline \multirow{8}{*}{ 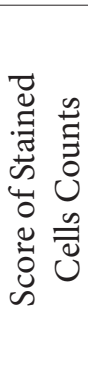 } & \multirow{2}{*}{1} & Count & 0 & 1 & 0 & 0 & 1 \\
\hline & & \% within pathology & $0.00 \%$ & $7.70 \%$ & $0.00 \%$ & $0.00 \%$ & $2.20 \%$ \\
\hline & & Count & 0 & 0 & 0 & 1 & 1 \\
\hline & & \% within pathology & $0.00 \%$ & $0.00 \%$ & $0.00 \%$ & $8.30 \%$ & $2.20 \%$ \\
\hline & & Count & 1 & 4 & 3 & 1 & 9 \\
\hline & & \% within pathology & $11.10 \%$ & $30.80 \%$ & $25.00 \%$ & $8.30 \%$ & $19.60 \%$ \\
\hline & \multirow{2}{*}{4} & Count & 8 & 8 & 9 & 10 & 35 \\
\hline & & \% within pathology & $88.90 \%$ & $61.50 \%$ & $75.00 \%$ & $83.30 \%$ & $76.10 \%$ \\
\hline \multirow{6}{*}{ 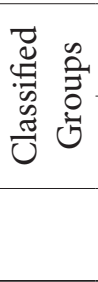 } & \multirow{2}{*}{$\begin{array}{l}\text { Low Expression } \\
\text { Group }\end{array}$} & Count & 0 & 1 & 0 & 0 & 1 \\
\hline & & \% within pathology & $0.00 \%$ & $7.70 \%$ & $0.00 \%$ & $0.00 \%$ & $2.20 \%$ \\
\hline & \multirow{2}{*}{$\begin{array}{l}\text { High Expression } \\
\text { Group }\end{array}$} & Count & 9 & 12 & 12 & 12 & 11 \\
\hline & & $\%$ within pathology & $100.00 \%$ & $92.30 \%$ & $100.00 \%$ & $100.00 \%$ & $23.90 \%$ \\
\hline & \multirow{2}{*}{ Total } & Count & $9(19.56 \%)$ & $13(26.08 \%)$ & $12(28.26 \%)$ & $12(26.08 \%)$ & $46(100.00 \%)$ \\
\hline & & \% within pathology & $100.00 \%$ & $100.00 \%$ & $100.00 \%$ & $100.00 \%$ & $100.00 \%$ \\
\hline
\end{tabular}

All mentioned markers are exclusively expressed in connective tissue cells except laminin which is expressed in epithelial tissue. In this study we assessed fascin, as another epithelial cell marker. Fascin is also known as the protein of motility $(11,12)$. No wonder that expression of fascin can be associated with aggressive and invasive behaviors $(28,29)$ as seen in many epithelial cancers $(13)$. Fascin is believed to be a biomarker that indicates aggressiveness and migration of tumors. However, our results contradict this hypothesis as we observed no significant upregulation of fascin in aggressive lesions. In addition, one meta-analysis study demonstrated that fascin may have potential as a novel biomarker for early identification of aggressive and metastatic tumors (12). In our study, the only statistically significant difference among the four lesions was the increased fascin expression in unicystic ameloblastoma in comparison to the other three. There is a possibility that fascin might be more expressed in carcinomas than cyst walls or odontogenic tumors. Also since the lesions of this study were mostly intra-bony, there were no epithelial barriers to their progression. Moreover these lesions do not metastasize. Considering these, we suggest that fascin might be more involved in cell invasion and migration (as in carcinomas) than local aggressiveness. Lee et al. suggested that fascin over-expression might enhance oral squamous cell carcinoma aggressiveness, possibly by interacting with E-cadherin expression (19). There is no E-cadherin interaction in progression of odontogenic lesion versus progression of carcinomas. Therefore, according to Lee theory (19), our suggestion based on more involvement of fascin in invasion and migration than local aggressiveness in benign odontogenic lesion is justifiable. Furthermore, Li et al. showed that fascin is an integral component of invadopodia -the finger-like protrusions using by cancer cells which help them invade into and degrade extracellular matrix- and it is important for the stability of actin in invadopodia (28). Epithelial cells of benign odontogenic lesions like DC, OKC or ameloblastoma that we assessed in this study do not use invadopodia for progression, and this may be a reason for less involvement of fascin in local aggressiveness.

It is accepted that immunohistochemistry is a complex metric due to the use of different scoring systems to assess the extent of staining in different specimens but the scoring of fascin is a continuous measurement and in most publications researchers categorized specimens into high/positive or low/negative fascin based on different semi-quantitatively assessed cut-off points (12). We also 
assessed the fascin expression in two groups of low and high expression as in most previous publications. However, this study has several limitations. First, we did not assess whether these lesions had perforated the cortical bone and invaded local soft tissue. Second, we just examined fascin expression and not other proteins or markers. We suggest more studies with more samples, and assessing expression of different proteins in the future.

\section{CONFLICT of INTEREST}

The authors declare no conflict of interest.

\section{REFERENCES}

1. Zhang FR, Tao LH, Shen ZY, Lv Z, Xu LY, Li EM. Fascin expression in human embryonic, fetal, and normal adult tissue. J Histochem Cytochem. 2008;56:193-9.

2. Lin-Jones J, Burnside B. Retina-specific protein fascin 2 is an actin cross-linker associated with actin bundles in photoreceptor inner segments and calycal processes. Invest Ophthalmol Vis Sci. 2007;48:1380-8.

3. Tubb B, Mulholland DJ, Vogl W, Lan ZJ, Niederberger C, Cooney A, Bryan J. Testis fascin (FSCN3): A novel paralog of the actinbundling protein fascin expressed specifically in the elongate spermatid head. Exp Cell Res. 2002;275:92-109.

4. Hashimoto Y, Kim DJ, Adams JC. The roles of fascins in health and disease. J Pathol. 2011;224:289-300.

5. Yamashiro S. Functions of fascin in dendritic cells. Crit Rev Immunol. 2012;32:11-21.

6. Khurana S, George SP. The role of actin bundling proteins in the assembly of filopodia in epithelial cells. Cell Adh Migr. 2011;5:409-20.

7. Ma Y, Reynolds LE, Li A, Stevenson RP, Hodivala-Dilke KM, Yamashiro S, Machesky LM. Fascin 1 is dispensable for developmental and tumour angiogenesis. Biol Open. 2013;2:1187-91.

8. Yamashiro S, Yamakita Y, Ono S, Matsumura F. Fascin, an actinbundling protein, induces membrane protrusions and increases cell motility of epithelial cells. Mol Bio Cell. 1998;9:993-1006.

9. Zhang F-R, Tao L-H, Shen Z-Y, Lv Z, Xu L-Y, Li E-M. Fascin expression in human embryonic, fetal, and normal adult tissue. J Histochem Cytochem. 2008;56:193-9.

10. Papaspyrou K, Brochhausen C, Schmidtmann I, Fruth K, Gouveris H, Kirckpatrick J, Mann W, Brieger J. Fascin upregulation in primary head and neck squamous cell carcinoma is associated with lymphatic metastasis. Oncol Lett. 2014;7:2041-6.

11. Xie JJ, Xu LY, Zhang HH, Cai WJ, Mai RQ, Xie YM, Yang ZM, Niu YD, Shen ZY, Li EM. Role of fascin in the proliferation and invasiveness of esophageal carcinoma cells. Biochem Biophys Res Commun. 2005;337:355-62.

12. Tan VY, Lewis SJ, Adams JC, Martin RM. Association of fascin-1 with mortality, disease progression and metastasis in carcinomas: A systematic review and meta-analysis. BMC Med. 2013;11:52.

13. Machesky LM, Li A. Fascin: Invasive filopodia promoting metastasis. Commun Integr Biol. 2010;3:263-70.

14. Arjonen A, Kaukonen R, Ivaska J. Filopodia and adhesion in cancer cell motility. Cell Adh Migr. 2011;5:421-30.
15. Neville BW, Damm DD, Allen CM, Chi AC. Oral and maxillofacial pathology. 4th ed. Riverport Lain: Elsevier; 2016:654.

16. Soluk-Tekkeşin M, Wright JM. The World Health Organization Classification of Odontogenic Lesions: A Summary of the Changes of the 2017 (4th) Edition. Turk Patoloji Derg. 2018;34: 1-18.

17. Bhargava D, Deshpande A, Pogrel MA. Keratocystic odontogenic tumour (KCOT)--a cyst to a tumour. Oral Maxillofac Surg. 2012;16:163-70.

18. Dunsche A, Babendererde O, Lüttges J, Springer IN. Dentigerous cyst versus unicystic ameloblastoma-differential diagnosis in routine histology. J Oral Pathol Med. 2003;32:486-91.

19. Lee TK, Poon RT, Man K, Guan XY, Ma S, Liu XB, Myers JN, Yuen AP. Fascin over-expression is associated with aggressiveness of oral squamous cell carcinoma. Cancer Lett. 2007;254:308-15.

20. Goncalves CK, Fregnani ER, Leon JE, Silva-Sousa YT, Perez DE. Immunohistochemical expression of p63, epidermal growth factor receptor (EGFR) and notch-1 in radicular cysts, dentigerous cysts and keratocystic odontogenic tumors. Braz Dent J. 2012;23:337-43.

21. Sharifi-Sistani N, Zartab H, Babakoohi S, Saghravanian N, Jamshidi S, Esmaili H, Mohtasham N, Zamanzadeh M, Abbaszadeh-Bidokhty H. Immunohistochemical comparison of the expression of $\mathrm{p} 53$ and MDM2 proteins in ameloblastomas and keratocystic odontogenic tumors. J Craniofac Surg. 2011;22:1652-6.

22. Shear M. The aggressive nature of the odontogenic keratocyst: Is it a benign cystic neoplasm? Part 3. Immunocytochemistry of cytokeratin and other epithelial cell markers. Oral Oncol. 2002;38:407-15.

23. Sreedhar G, Raju MV, Metta KK, Manjunath S, Shetty S, Agarwal RK. Immunohistochemical analysis of factors related to apoptosis and cellular proliferation in relation to inflammation in dentigerous and odontogenic keratocyst. J Nat Sci Biol Med. 2014;5:112-5.

24. Tekkesin MS, Mutlu S, Olgac V. The role of RANK/RANKL/ OPG signalling pathways in osteoclastogenesis in odontogenic keratocysts, radicular cysts, and ameloblastomas. Head Neck Pathol. 2011;5:248-53.

25. Poomsawat S, Punyasingh J, Vejchapipat P. Expression of basement membrane components in odontogenic tumors. Oral Surg Oral Med Oral Pathol Oral Radiol Endod. 2007;104:666-75.

26. da Silva TA, Batista AC, Mendonca EF, Leles CR, Fukada S, Cunha FQ. Comparative expression of RANK, RANKL, and OPG in keratocystic odontogenic tumors, ameloblastomas, and dentigerous cysts. Oral Surg Oral Med Oral Pathol Oral Radiol Endod. 2008;105:333-41.

27. Qian Y, Huang HZ. The role of RANKL and MMP-9 in the bone resorption caused by ameloblastoma. J Oral Pathol Med. 2010;39:592-8.

28. Li A, Dawson JC, Forero-Vargas M, Spence HJ, Yu X, König I, Anderson K, Machesky LM. The actin-bundling protein fascin stabilizes actin in invadopodia and potentiates protrusive invasion. Curr Biol. 2010;20:339-45.

29. Anilkumar N, Parsons M, Monk R, Ng T, Adams JC. Interaction of fascin and protein kinase Calpha: A novel intersection in cell adhesion and motility. EMBO J. 2003;22:5390-402. 